\title{
IDENTIFIKASI KANDUNGAN SENYAWA METABOLIT SEKUNDER DAN UJI BIOAKTIVITAS TERHADAP LARVA UDANG (Artemia salina Leach.) EKSTRAK DAUN KECAPI (Sandoricum koetjape Merr.)
}

\author{
Destri Erawaty*, Aditya Fridayanti, Laode Rijai \\ Laboratorium Penelitian dan Pengembangan FARMAKA TROPIS, Fakultas Farmasi, Universitas Mulawarman, \\ Samarinda, Kalimantan Timur \\ *Coresponding author email: destri_erawaty@yahoo.com
}

\begin{abstract}
Secondary metabolites identification and bioactivity of santol leaves extract (S.koetjape Merr.) against Artemia salina Leach has been done. Secondary metabolite identification was done by testing santol leaves extract and fractions against reagent, whereas the bioactivity tests carried out by Brine Shrimp Lethality Test (BSLT) method. Santol leaves extract was extracted using methanol solvent and was fractioned using $n$-hexane, ethyl acetate and $n$-butanol solvents. The results showed that the santol leaves extract contain flavanoid, saponin, tannin, karatenoid, fenol, steroid, and triterpenoid. $L C_{50}$ value of each crude extract, $n$-hexane fraction, ethyl acetate fraction, and n-butanol fraction was 190.12 ppm, 189.23 ppm, 299.23 ppm, and 301.99 ppm.
\end{abstract}

Keywords: S.koetjape Merr, Artemia salina Leach, BSLT

ABSTRAK

Penelitian identifikasi metabolit sekunder dan bioaktivitas ekstrak daun kecapi (S.koetjape Merr.) terhadap Larva Artemia salina Leach telah dilakukan. Identifikasi metabolit sekunder dilakukan dengan melakukan uji ekstrak dan fraksi daun kecapi terhadap pereaksi, sedangkan uji bioaktivitas dilakukan dengan metode Brine Shrimp Lethality Test (BSLT). Ekstrak daun kecapi telah diekstrak dengan menggunakan pelarut metanol dan difraksi menggunakan pelarut $n$-heksana, etil asetat dan n-butanol. Hasil penelitian menunjukkan bahwa ekstrak daun kecapi mengandung golongan flavanoid, saponin, tannin, karatenoid, fenol, steroid, dan terpenoid. Nilai $\mathrm{LC}_{50}$ dari masing-masing ekstrak kasar, fraksi n-heksana, fraksi etil asetat, dan fraksi n-butanol adalah 190.12 ppm, 189.23 ppm, 299.23 ppm dan 301.99 ppm.

Kata kunci : S.koetjape Merr, Artemia salina Leach, BSLT

Submitted on: 5 January 2017 Accepted on: 15 February 2017

DOI: https://doi.org/10.25026/jsk.v1i6.64

\section{PENDAHULUAN}

Pemanfaatan tanaman sebagai obat sudah dilakukan dari dimulainya peradaban manusia. Tanaman memiliki berbagai bahan kimia yang mempunyai sejuta manfaat termasuk untuk obat berbagai penyakit. Kemampuan meracik tanaman berkhasiat obat dan jamu atau ramuan merupakan warisan turun temurun dan obat tradisional tersebut telah mengakar kuat di masyarakat. Tanaman yang merupakan bahan baku obat tradisional tersebut, terdapat diseluruh wilayah Indonesia.

Banyak tumbuhan obat mempunyai potensi sebagai obat antikanker. Dalam penggunaannya, tumbuhan obat ini dapat bisa dipakai bersamaan dengan pengobatan medis, setelah pengobatan medis selesai dilakukan atau sebelum mendapatkan pengobatan medis. Di Indonesia, penggunaan tumbuhan obat memang belum diakui secara resmi, meski dari pengalaman 
Identifikasi kandungan senyawa metabolit sekunder dan uji bioaktivitas terhadap larva udang (artemia salina leach.) Ekstrak daun kecapi (sandoricum koetjape merr.)

turun temurun jelas bahwa tumbuhan obat mempunyai manfaat yang sangat besar untuk kesehatan. Berbeda dengan di negara Cina dan India yang sudah mengakui cara pengobatan tradisional secara resmi. Padahal Indonesia merupakan sumber tumbuhan obat terbesar kedua di dunia setelah Brasil. Saat ini diketahui terdapat sekitar 40 jenis tumbuhan obat asli Indonesia yang dipercaya mempunyai efek antikanker. Sehingga sayang sekali jika tidak dimanfaatkan secara optimal [1].

Salah satu tumbuhan asli Indonesia yang dapat digunakan sebagai obat tradisional adalah tanaman kecapi (S.koetjapi Merr.). Kecapi merupakan salah satu anggota famili Sapindales. Berdasarkan literatur daun kecapi (S.koetjapi Merr.) mengandung senyawa flavonoid, saponin, fenol, steroid dan tanin. Daun kecapi (S.koetjapi Merr.) diduga memiliki banyak manfaat yang sangat luas sebagai obat, seperti obat batuk, obat mulas, keputihan, pengobatan cacing gelang, kurap, obat kembung, diare, sakit pinggang, serta untuk penguat tubuh wanita setelah melahirkan [2].

Metode BSLT merupakan salah satu metode yang digunakan untuk penapisan awal senyawa-senyawa yang diduga memiliki senyawa aktif. Penelitian ini menggunakan Artemia salina Leach sebagai hewan uji. Parameter yang digunakan untuk menunjukkan adanya aktivitas biologi suatu senyawa yaitu jumlah kematian Artemia salina Leach. Metode ini dilakukan dengan menentukan besarnya $\mathrm{LC}_{50}$ selama 24 jam. Suatu ekstrak tanaman atau fraksi ekstrak tanaman yang mempunyai $\mathrm{LC}_{50}$ kurang dari $1000 \mu \mathrm{g} / \mathrm{mL}$ dapat diduga memiliki aktivitas seperti sitotoksik, anti mikroba, dan pestisida [3].
Suatu ekstrak dinyatakan bersifat aktif menurut metode BSLT (Brine Shrimp Lethality Test) ini jika memliki $\mathrm{LC}_{50}$ kurang dari $1000 \mu \mathrm{g} / \mathrm{ml}$. Jika hasil uji BSLT (Brine Shrimp Lethality Test) menunjukkan bahwa ekstrak tumbuhan bersifat aktif maka dapat dikembangkan ke penelitian lebih lanjut untuk mengisolasi senyawa aktivitas tumbuhan sebagai usaha pengembangan obat alternatif dan dapat dikembangkan juga ke penelitian lebih lanjut untuk meneliti khasiat-khasiat lain dari ekstrak tersebut [4]

Berdasarkan hal tersebut dilakukan penelitian identifikasi golongan metabolit sekunder dan uji bioaktivitas ekstrak daun menggunakan metode BSLT. Penelitian ini merupakan penelitian pendahuluan untuk mengetahui bioaktivitas ekstrak daun kecapi untuk pemanfaatannya sebagai sitotoksik, anti mikroba, dan pestisida.

Penelitian ini bertujuan untuk mengetahui rendemen ekstrak, metabolit sekunder yang terkandung, mengetahui bioaktivitas ektrak, dan berapa nilai $\mathrm{LC}_{50}$ dari ekstrak daun kecapi terhadap larva udang Artemia salina Leach.

\section{METODE PENELITIAN}

\section{Bahan}

Bahan yang diteliti adalah simplisia daun kecapi (S.koetjapi Merr.). Pelarut metanol digunakan untuk proses ekstraksi dan fraksinasi. Pelarut $\mathrm{n}$-heksan, etil asetat, n-butanol digunakan untuk fraksinasi caircair. Larva udang Artemia salina Leach bioindikator uji. Pereaksi Dragon droff, Meyer, Asam sulfat pekat, Asam asetat, Kloroform, Ferri klorida, kalium heksasianoferat (III), metanol, pita magnesium, asam klorida pekat, natrium klorida, natrium hidroksida digunakan pengujian metabolit sekunder. Air laut 
untuk media penetasan dan tempat hidup bioindikator uji.

\section{Alat}

Alat-alat yang digunakan pada penelitian adalah neraca analitik (Precisa $X B 4200 C^{\circledR}$, Precisa XT $220 A^{\circledR}$ ), toples, botol selai, batang pengaduk, gelas kimia $\left(\right.$ Pyrex $\left.^{\circledR}\right)$, gelas ukur $\left(\right.$ Pyrex $\left.^{\circledR}\right)$, labu ukur $\left(\right.$ Pyrex $\left.^{\circledR}\right)$, tabung pereaksi $\left(\right.$ Pyrex $\left.^{\circledR}\right)$, botol timbang, spoit, corong pisah, rotary evaporator $\left(\right.$ Heidolph $\left.^{\circledR}\right)$, pipet tetes, pipet volume $\left(\right.$ Pyrex $\left.^{\circledR}\right)$, cawan porselin, kaca arloji, spatula, pinset, rak tabuk reaksi, aluminium foil, botol vial, penangas air, kaca aquarium, aerator, seperangkat alat penerangan, statif, selang plastik, kertas saring Whatman, pompa vakum.

\section{Prosedur Pengujian Penelitian}

Pengujian identifikasi metabolit sekunder pada ekstrak dan fraksi daun kecapi yakni dengan cara mengamati perubahan reaksi menggunakan reagen kimia. Golongan metabolit sekunder yang diuji adalah alkaloid, flavanoid, karotenoid, saponin, senyawa fenol, steroid/triterpenoid, dan tannin.

Pengujian bioaktivitas ekstrak daun kecapi tehadap larva udang Artemia salina Leach. Larva udang Artemia salina Leach 10 ekor dimasukkan ke dalam masingmasing vial yang berisi ekstrak dengan berbagai konsentrasi. Konsentrasi yang digunakan $50 \mathrm{ppm}, 150 \mathrm{ppm}, 250 \mathrm{ppm}, 350$ ppm, dan 450 ppm untuk ekstrak metanol dan fraksi n-heksan. Konsentrasi $50 \mathrm{ppm}$, 200 ppm, 350 ppm, 500 ppm, dan 650 ppm untuk fraksi etil asetat dan fraksi n-butanol. Dibuat stok ragi sebanyak $3 \mathrm{mg}$ dalam 5
$\mathrm{mL}$ air laut sebagai sumber makanan bioindikator uji. $\mathrm{Ke}$ dalam vial-vial tersebut dimasukkan 1 tetes ragi. Vial-vial uji kemudian disimpan di tempat yang cukup mendapat sinar lampu. Pengamatan dilakukan selama 24 jam dan dihitung jumlah larva yang mati. Jumlah larva udang Artemia salina Leach yang mati dicatat dan dihitung $\mathrm{LC}_{50}$ dengan menggunakan analisis Reed and Muench.

\section{HASIL DAN PEMBAHASAN}

Rendemen dianalisis dengan menghitung persentase ekstrak dan fraksi dengan cara membandingkan bobot hasil proses (ekstrak dan fraksi) dengan bobot awal (sampel basah, sampel kering, dan ekstrak metanol yang difraksinasi). Ekstrak metanol yang digunakan untuk fraksinasi dikonversikan terlebih dahulu terhadap bobot ekstrak metanol. Perhitungan rendemen ini bertujuan untuk mengetahui persentase bobot ekstrak dan fraksi yang dihasilkan terhadap bobot awal sampel.

Dari Tabel 2 diketahui bahwa rendemen ekstrak kasar metanol terhadap sampel segar dan kering berturut turut adalah $7,62 \%$ dan $21,18 \%$. Rendemen tertinggi dari fraksi daun kecapi adalah fraksi n-heksana sebesar 50,91\% terhadap ekstrak kasar metanol dan terkecil adalah ekstrak fraksi n-butanol sebesar 24,97\% terhadap ekstrak kasar metanol, hasil tersebut menunjukan bahwa ekstrak daun kecapi memiliki kandungan senyawa non polar yang lebih banyak daripada senyawa polarnya. 
Identifikasi kandungan senyawa metabolit sekunder dan uji bioaktivitas terhadap larva udang (artemia salina leach.) Ekstrak daun kecapi (sandoricum koetjape merr.)

Tabel 1. Berat Ekstrak dan Fraksi Daun Kecapi terhadap sampel segar, sampel kering dan ekstrak metanol

\begin{tabular}{ccc}
\hline No & Sampel dan Ekstrak & Berat $(\mathrm{g})$ \\
\hline 1 & Sampel Segar & 1876 \\
2 & Sampel kering & 675 \\
3 & Ekstrak metanol & 142,97 \\
4 & Fraksi n- heksana & 15,24 \\
5 & Fraksi etil asetat & 9,441 \\
6 & Fraksi n- butanol & 7,492 \\
\hline
\end{tabular}

Tabel 2. Data Rendamen Ekstrak Daun Kecapi

\begin{tabular}{ccccc}
\hline \multirow{2}{*}{ No } & \multirow{2}{*}{ Ekstrak Daun Kecapi } & \multicolumn{3}{c}{ Rendemen Ekstrak Daun Kecapi (\%) } \\
\cline { 3 - 5 } & & Sampel Basah & Sampel Kering & $\begin{array}{c}\text { Ekstrak Metanol } \\
1876 \mathrm{~g}\end{array}$ \\
\hline 1 & Ekstrak Kasar & 7,62 & $675 \mathrm{~g}$ & - \\
2 & Fraksi $n$-heksana & 3,87 & 21,18 & 50,91 \\
3 & Fraksi Etil asetat & 2,39 & 10,76 & 31,47 \\
4 & Fraksi $n$-butanol & 1,90 & 6,66 & 24,97 \\
\hline
\end{tabular}

Tabel 3. Hasil Uji Kandungan Metabolit Sekunder Daun Kecapi

\begin{tabular}{ccccc}
\hline \multirow{2}{*}{ Metabolit Sekunder } & \multicolumn{5}{c}{ Perlakuan } \\
\cline { 2 - 5 } & $\begin{array}{c}\text { Ekstrak } \\
\text { metanol }\end{array}$ & $\begin{array}{c}\text { Fraksi } \\
\text { n-heksana }\end{array}$ & $\begin{array}{c}\text { Fraksi } \\
\text { etil asetat }\end{array}$ & $\begin{array}{c}\text { Fraksi } \\
\text { n-butanol }\end{array}$ \\
\hline Alkaloid & - & - & - & - \\
Flavanoid & + & + & + & + \\
Karatenoid & + & + & + & + \\
Saponin & + & + & + & - \\
Senyawa Fenol & + & + & + & + \\
Steroid dan Triterpenoid & - & + & + & + \\
Tanin & + & + & + & + \\
\hline
\end{tabular}

Keterangan :

Data berupa data kualitatif (-) dan (+), dimana:

(-) : Tidak teridentifikasi metabolit sekunder

(+) : Teridentifikasi metabolit sekunder 
Berdasarkan hasil pengujian kandungan metabolit sekunder ini disimpulkan bahwa daun kecapi mengandung golongan senyawa flavanoid, karatenoid, tanin, saponin, fenol, steroid dan triterpenoid. Bioaktivitas larva Artemia salina Leach dilihat dari kemampuan yaitu tinggi atau rendahnya konsentrasi yang digunakan oleh ekstrak daun kecapi untuk mematikan larva. Pengujian ini juga menggunakan kontrol negatif. Kontrol negatif adalah sampel yang perlakuannya tidak ditambahkan ekstrak yaitu hanya bioindikator dan media air laut, sehingga diharapkan kontrol negatif tidak beraktivitas larvasida yaitu semua larva udang yang digunakan hidup yang mengartikan media, lingkungan dan pengaruh lain tidak mempengaruhi pengujian yang telah dilakukan.

Terlihat pada Gambar 1 terjadi peningkatan konsentrasi ekstrak methanol daun kecapi dalam kemampuan membunuh hewan uji larva udang, yaitu dengan bertambahnya larva udang yang mati. Ini terlihat dari hasil analisis dengan metode Reed and Muench dengan nilai $\mathrm{LC}_{50} 190,12$ ppm. Dapat terlihat pada titik pertemuan antara akumulasi kematian dengan akumulasi yang hidup adalah estimasi nilai $\mathrm{LC}_{50}$. Sumbu ini berada pada grafik antara $\log$ konsentrasi 2,176 - 2,397. Nilai LC $_{50}$ ekstrak metanol daun kecapi menunjukkan bahwa ekstrak metanol daun kecapi berpotensi antimikroba ( $\left.\mathrm{LC}_{50} 30-200 \mathrm{ppm}\right)$.

Tabel 4 Hasil Uji Ekstrak Metanol Terhadap Larva Udang Artemia salina

\begin{tabular}{|c|c|c|c|c|c|c|c|}
\hline \multirow{2}{*}{ Konsentrasi } & \multirow{2}{*}{$\begin{array}{c}\text { Log } \\
\text { Konsentrasi }\end{array}$} & \multicolumn{2}{|c|}{ Jumlah } & \multicolumn{2}{|c|}{ Terakumulasi } & \multirow{2}{*}{$\begin{array}{c}\text { Rasio } \\
\text { mati : total } \\
\text { Terakumulasi } \\
\mathrm{x}:(\mathrm{x}+\mathrm{y})\end{array}$} & \multirow{2}{*}{$\begin{array}{c}\begin{array}{c}\text { Mortalitas } \\
(\%)\end{array} \\
\text { Rasio x } \\
100 \%\end{array}$} \\
\hline & & Mati & Hidup & $\begin{array}{l}\text { Mati } \\
\text { (x) }\end{array}$ & $\begin{array}{c}\text { Hidup } \\
\text { (y) }\end{array}$ & & \\
\hline $50 \mathrm{ppm}$ & 1,698 & 9 & 41 & 9 & 101 & 0,080 & 8 \\
\hline $150 \mathrm{ppm}$ & 2,176 & 25 & 25 & 34 & 60 & 0,362 & 36,2 \\
\hline $250 \mathrm{ppm}$ & 2,397 & 33 & 17 & 67 & 35 & 0,657 & 65,7 \\
\hline $350 \mathrm{ppm}$ & 2,544 & 38 & 12 & 105 & 18 & 0,854 & 85,4 \\
\hline $450 \mathrm{ppm}$ & 2,653 & 44 & 6 & 149 & 6 & 0,960 & 96 \\
\hline
\end{tabular}


Identifikasi kandungan senyawa metabolit sekunder dan uji bioaktivitas terhadap larva udang (artemia salina leach.) Ekstrak daun kecapi (sandoricum koetjape merr.)

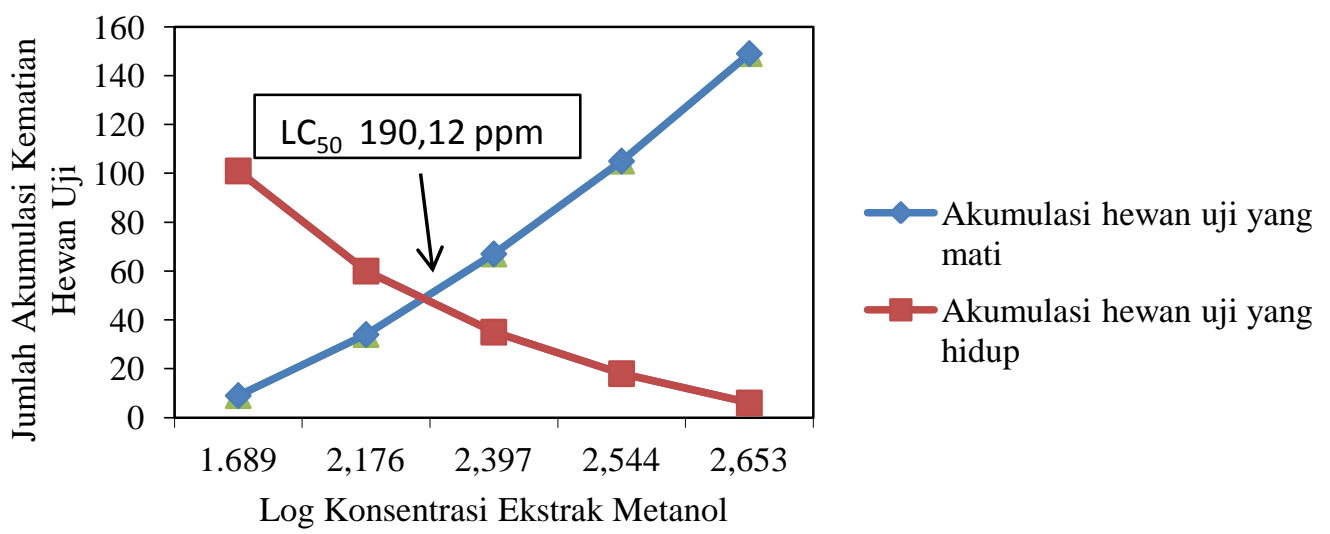

Gambar 1 Grafik LC $C_{50}$ Ekstrak Metanol Daun Kecapi

Tabel 5 Hasil Uji Fraksi N-Heksan Terhadap Larva Udang Artemia salina

\begin{tabular}{cccccccc}
\hline & & \multicolumn{2}{c}{ Jumlah } & Terakumulasi & $\begin{array}{c}\text { Rasio } \\
\text { mati : total }\end{array}$ & $\begin{array}{c}\text { Mortalitas } \\
(\%)\end{array}$ \\
\cline { 3 - 8 } Konsentrasi & $\begin{array}{c}\text { Log } \\
\text { Konsentrasi }\end{array}$ & Mati & Hidup & $\begin{array}{c}\text { Mati } \\
(\mathrm{x})\end{array}$ & $\begin{array}{c}\text { Hidup } \\
(\mathrm{y})\end{array}$ & $\begin{array}{c}\text { Terakumulasi } \\
\mathrm{x}:(\mathrm{x}+\mathrm{y})\end{array}$ & $\begin{array}{c}\text { Rasio } \mathrm{x} \\
100 \%\end{array}$ \\
\hline $50 \mathrm{ppm}$ & 1,698 & 8 & 42 & 8 & 98 & 0,075 & 7,5 \\
$150 \mathrm{ppm}$ & 2,176 & 20 & 30 & 28 & 56 & 0,333 & 33,3 \\
$250 \mathrm{ppm}$ & 2,397 & 32 & 18 & 60 & 26 & 0,697 & 69,7 \\
$350 \mathrm{ppm}$ & 2,653 & 42 & 8 & 102 & 8 & 0,927 & 92,7 \\
\hline
\end{tabular}

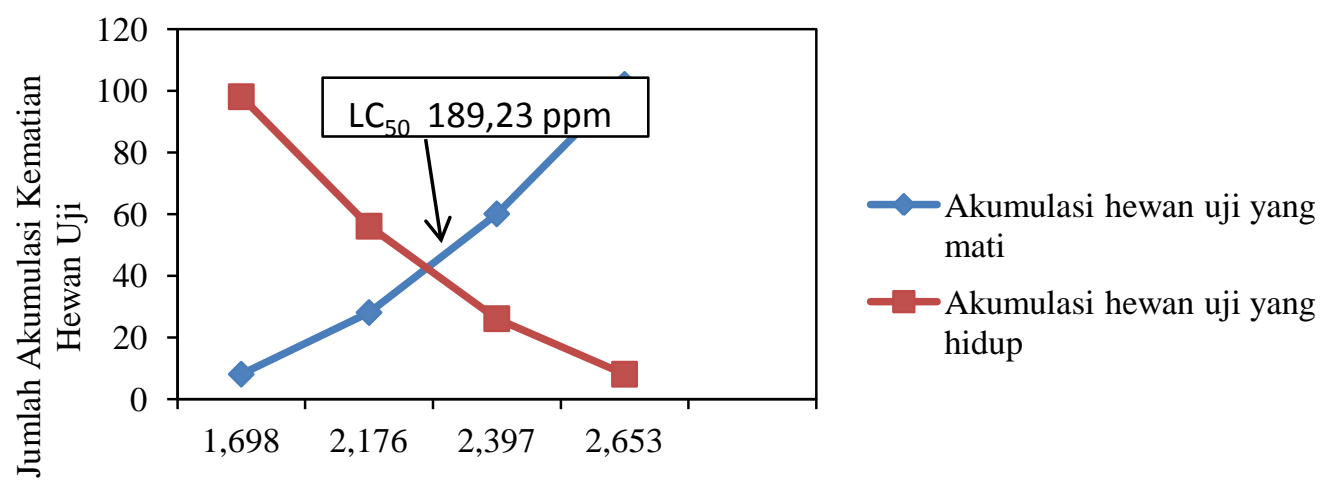

Log Konsentrasi Fraksi n-Heksana

Gambar 2 Grafik $L C_{50}$ Fraksi n-Heksan Daun Kecapi 
Identifikasi kandungan senyawa metabolit sekunder dan uji bioaktivitas terhadap larva udang (artemia salina leach.) Ekstrak daun kecapi (sandoricum koetjape merr.)

Tabel 6 Hasil Uji Fraksi Etil Asetat Terhadap Larva Udang Artemia salina

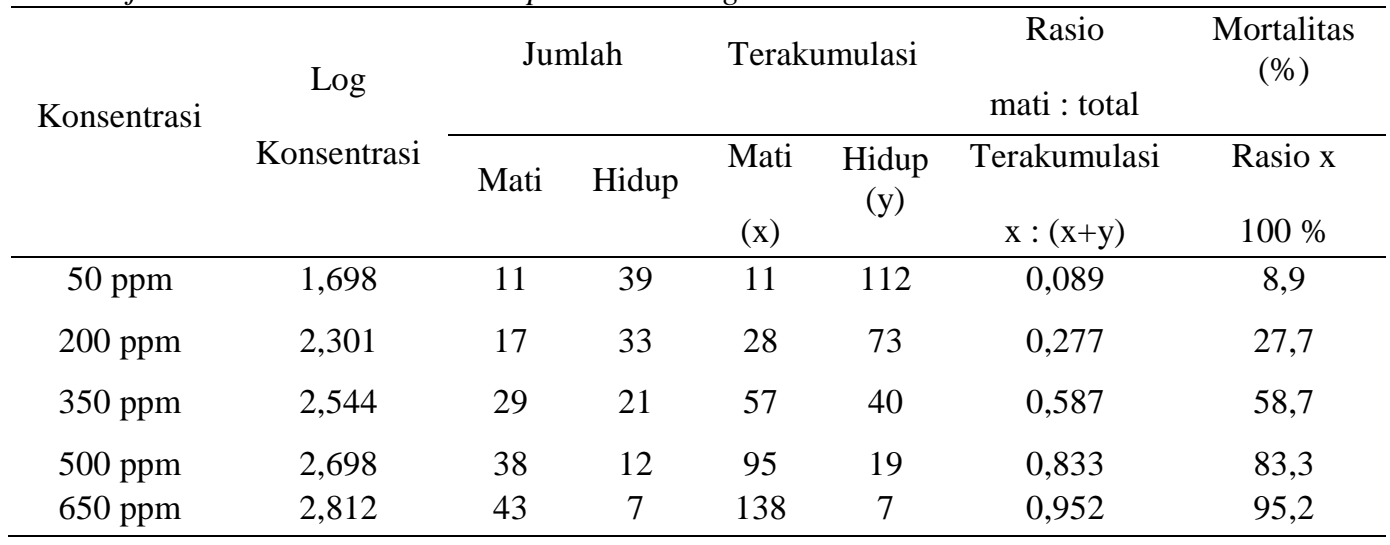

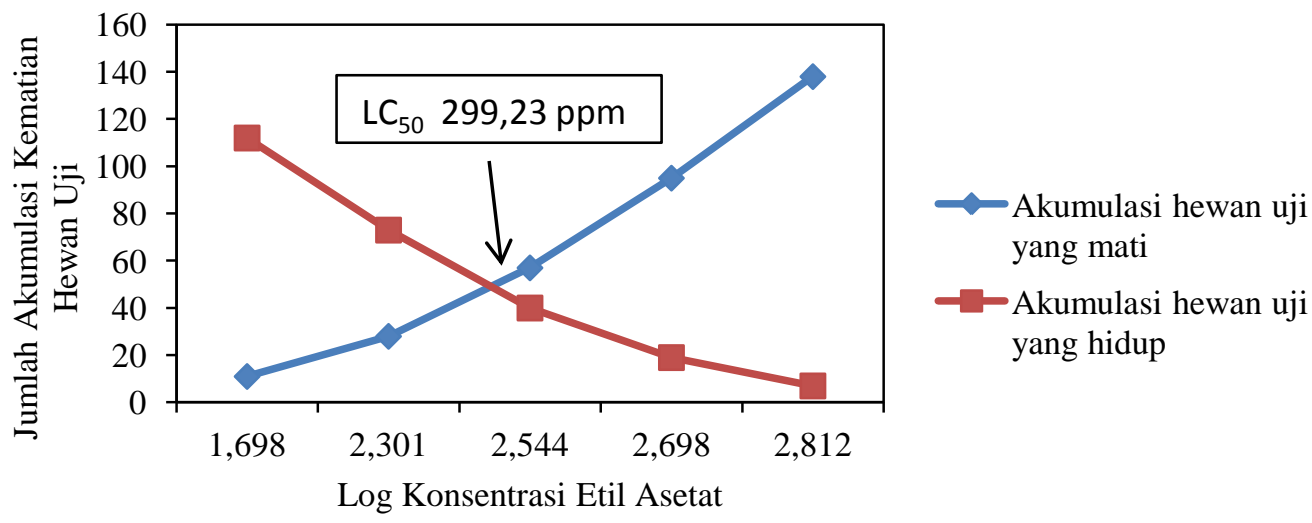

Gambar 3 Grafik $L C_{50}$ Fraksi Etil Asetat Daun Kecapi

Terlihat pada Gambar 2 terjadi peningkatan konsentrasi fraksi n-Heksan daun kecapi dalam kemampuan membunuh hewan uji larva udang, yaitu dengan bertambahnya larva udang yang mati. Ini terlihat dari hasil analisis dengan metode Reed and Muench dengan nilai $\mathrm{LC}_{50}$ 189,23 ppm. Dapat terlihat pada titik pertemuan antara akumulasi kematian dengan akumulasi yang hidup adalah estimasi nilai $\mathrm{LC}_{50}$. Sumbu ini berada pada grafik antara log konsentrasi 2,176 - 2,397. Nilai LC $_{50}$ menunjukkan bahwa fraksi n-heksan daun kecapi berpotensi antimikroba ( $\mathrm{LC}_{50} 30$ 200 ppm).Terlihat pada Gambar 3 terjadi peningkatan konsentrasi fraksi etil asetat dalam kemampuan membunuh hewan uji larva udang, yaitu dengan bertambahnya larva udang yang mati. Ini terlihat dari hasil analisis dengan metode Reed and Muench dengan nilai LC $_{50}$ 299,23 ppm. Dapat terlihat pada titik pertemuan antara akumulasi kematian dengan akumulasi yang hidup adalah estimasi nilai $\mathrm{LC}_{50}$. Sumbu ini berada pada grafik antara log konsentrasi 2,301 - 2,544. Nilai LC $_{50}$ 
Identifikasi kandungan senyawa metabolit sekunder dan uji bioaktivitas terhadap larva udang (artemia salina leach.) Ekstrak daun kecapi (sandoricum koetjape merr.)

menunjukkan bahwa fraksi etil asetat daun kecapi berpotensi sebagai pestisida $\left(\mathrm{LC}_{50}\right.$ 200-1000 ppm).

Terlihat pada Gambar 4 terjadi peningkatan konsentrasi fraksi n-butanol dalam kemampuan membunuh hewan uji larva udang, yaitu dengan bertambahnya larva udang yang mati. Ini terlihat dari hasil analisis dengan metode Reed and Muench dengan nilai $\mathrm{LC}_{50} 301,99 \mathrm{ppm}$.
Dapat terlihat pada titik pertemuan antara akumulasi kematian dengan akumulasi yang hidup adalah estimasi nilai $\mathrm{LC}_{50}$. Sumbu ini berada pada grafik antara $\log$ konsentrasi 2,301 - 2.544. Nilai $\mathrm{LC}_{50}$ menunjukkan bahwa fraksi n-butanol daun kecapi berpotensi pestisida $\left(\mathrm{LC}_{50} 200-1000\right.$ $\mathrm{ppm})$. Nilai $\mathrm{LC}_{50}$ ekstrak dan fraksi daun kecapi dapat dilihat pada Tabel.8.

Tabel 7. Hasil Uji Fraksi Etil Asetat Terhadap Larva Udang Artemia salina

\begin{tabular}{cccccccc}
\hline & & \multicolumn{2}{c}{ Jumlah } & Terakumulasi & $\begin{array}{c}\text { Rasio } \\
\text { mati : total }\end{array}$ & $\begin{array}{c}\text { Mortalitas } \\
(\%)\end{array}$ \\
\cline { 3 - 8 } Konsentrasi & $\begin{array}{c}\text { Log } \\
\text { Konsentrasi }\end{array}$ & $\begin{array}{c}\text { Mat } \\
\mathrm{i}\end{array}$ & Hidup & $\begin{array}{c}\text { Mati } \\
(\mathrm{x})\end{array}$ & $\begin{array}{c}\text { Hidup } \\
(\mathrm{y})\end{array}$ & $\begin{array}{c}\text { Terakumulasi } \\
\mathrm{x}:(\mathrm{x}+\mathrm{y})\end{array}$ & $\begin{array}{c}\text { Rasio x } \\
100 \%\end{array}$ \\
\hline $50 \mathrm{ppm}$ & 1,698 & 8 & 42 & 8 & 144 & 0,065 & 6,5 \\
$200 \mathrm{ppm}$ & 2,301 & 18 & 32 & 26 & 72 & 0,265 & 26,5 \\
$350 \mathrm{ppm}$ & 2,544 & 30 & 20 & 56 & 40 & 0,583 & 58,3 \\
$500 \mathrm{ppm}$ & 2,698 & 37 & 13 & 93 & 20 & 0,823 & 82,3 \\
$650 \mathrm{ppm}$ & 2,812 & 43 & 7 & 136 & 7 & 0,951 & 95,1 \\
\hline
\end{tabular}

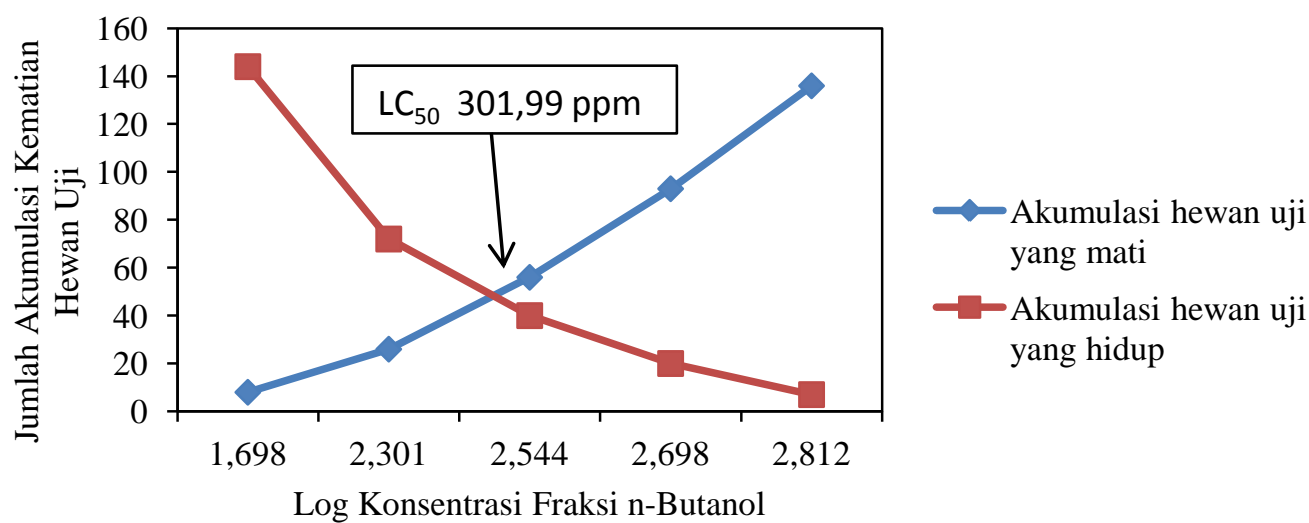

Gambar 4 Grafik LC $_{50}$ Fraksi n-Butanol Daun Kecapi

Tabel 8 Nilai LC $_{50}$ Ekstrak Daun Kecapi 


\begin{tabular}{llc}
\hline No. & Sampel & LC $_{50}(\mathrm{ppm})$ \\
\hline 1. & Ekstrak kasar (metanol) & 190,12 \\
2. & Fraksi n-heksana & 189,23 \\
3. & Fraksi etil asetat & 299,23 \\
4. & Fraksi n-butanol & 301,99 \\
\hline
\end{tabular}

Dengan membandingkan nilai $\mathrm{LC}_{50}$ ekstrak dan masing-masing fraksi daun kecapi dapat diketahui bahwa yang paling efektif terhadap Artemia salina Leach adalah ekstrak fraksi n-heksan daun kecapi. Berdasarkan hal tersebut dapat dikatakan dalam hal ini semua fraksi yang ada pada ekstrak daun kecapi mengandung masingmasing metabolit sekunder yang sesuai dengan tingkat polaritas sehingga semua fraksi aktif dalam membunuh larva udang uji.

\section{KESIMPULAN}

Hasil pengujian bioaktivitas terhadap larva udang Artemia salina Leach. diperoleh nilai $\mathrm{LC}_{50}$ masing-masing yaitu ekstrak metanol terhadap larva udang Artemia salina Leach LC $_{50}$ 190,12 ppm, fraksi n-heksana terhadap larva udang Artemia salina Leach $\mathrm{LC}_{50} 189,23 \mathrm{ppm}$, fraksi etil asetat terhadap larva udang Artemia salina Leach. LC L0 $_{50}$ 299,23 dan fraksi n-butanol terhadap larva udang Artemia salina Leach $\mathrm{Lc}_{50} 301,99$ ppm.

\section{UCAPAN TERIMA KASIH}

Peneliti menyampaikan terima kasih yang sebesar-besarnya kepada staf laboran Kimia Fakultas Farmasi Universitas Mulawarman Samarinda. Kepada saudari Pindo Hardika Putri Abiyadh Noor, S.Farm yang telah mau bekerja sama tentang penelitian tanaman kecapi ini.

\section{DAFTAR PUSTAKA}

[1]. Mangan Y. 2005. Cara Bijak Menaklukan Kanker. PT.Agro Media Pustaka. Depok

[2]. Tinggen, I N., 2000, Taru Premara, Pustaka Leluhur Eka Cipta; Singaraja

[3]. Colegate, Steven M. dan Russell J.Molyneux. 1993. Bioactive Natural Products: Detection, Isolation, and Structural Determination. CRC Press Inc: Florida.

[4]. Hendrawati, 2009, Penelitian Uji Toksisitas Akut Ekstrak Etanol daun Kemangi (Ocicum sanctum Linn.) terhadap Larva Artemia Salina Leach. dengan Metode Brine Shrimp Lethality Test (BSLT), Fakultas Kedokteran Jurusan kedokteran Universitas Dipenogoro, Semarang. 